\section{Oxidativer pulmonaler Stress unter zytoreduktiver Therapie}

\section{Einleitung}

In der Therapie solider Tumoren zeigt die kombinierte RadioChemotherapie ermutigende Ergebnisse hinsichtlich Remission und Überlebenszeit [1,2]. Für zahlreiche Tumorentitäten konnte so ein erfolgversprechender Therapiestandard definiert werden. Neben einer besseren lokalen Kontrolle ist die multimodale Therapie jedoch auch mit dem häufigeren Auftreten von Nebenwirkungen behaftet. So werden, insbesondere bei simultaner Verwendung höherer Strahlendosen im Thoraxbereich und strahlensensibilisierender zytoreduktiver Substanzen, häufig pulmonale Nebenwirkungen beobachtet $[3,4,5]$. Wochen bis Monate nach Therapie können lebensbedrohliche Pneumonitiden und Fibrosierungen des Lungenparenchyms das prognostische Bild des Patienten erheblich verschlechtern $[6,7,8]$. Damit beinhaltet die kombinierte Radio-Chemotherapie von z. B. Bronchial- oder Mammakarzinomen oft ein Abwägen zwischen Dosiseskalation und pulmonalen Nebenwirkungen.

Unzureichende Kenntnisse über die Mechanismen derartiger Lungenschädigungen erschwerten bisher die Beeinflussung der pulmonalen Komplikationen. Zunehmend erlangen jedoch reaktive Sauerstoffverbindungen (ROS) als auslösende Ursache dieser Folgeschäden Beachtung. Unter der Bezeichnung „ROS - Reactive Oxygen Species“ werden freie Radikale, also Moleküle mit einem oder mehreren ungepaarten Elektronen, sowie sauerstoffhaltige Verbindungen mit außerordentlich hoher Reaktionsbereitschaft zusammengefasst $[9,10]$. Bedingt durch ihre Reaktivität verfügen ROS über ein hohes Potenzial für typische Reaktionskaskaden, in denen Biomoleküle bis zum Funktionsverlust verändert werden können [10]. Ihre Einwirkung auf biologische Gewebe kann zu einem komplexen, sich selbst verstärkenden ROS- und Zytokin-Networking führen, das letztendlich in einer Fibroblastenaktivierung mündet $[11,12,13]$.

Die Lunge ist außerordentlich anfällig für radikalbedingte Schäden und deren Folgezustände [14]. Dies ist insbesondere

Pneumologie 2000; 54: $201-211$

(c) Georg Thieme Verlag Stuttgart · New York ISSN 0934-8387
T. Beinert ${ }^{1}$, D. Binder ${ }^{1}$, M. Stuschke², C. Oehm³, R. A. Jörres ${ }^{4}, M$. Schweigert ${ }^{1}, M$. Seemann, H.-G. Mergenthaler ${ }^{5}$, J. Behr ${ }^{6}$, M. Fleischhacker ${ }^{1}$, K. Possinger ${ }^{1}$

${ }^{1}$ Medizinische Klinik und Poliklinik m. S. Hämatologie und Onkologie, Charité, Campus Mitte, Berlin

${ }^{2}$ Klinik und Poliklinik für Strahlentherapie, Charité, Campus Mitte, Berlin

3 Johanniter-Krankenhaus, Fachklinik für Pneumologie, Treuenbrietzen

${ }^{4}$ Krankenhaus Großhansdorf, Zentrum für Pneumologie und Thoraxchirurgie

${ }^{5}$ Medizinische Klinik für Onkologie, Katharinenhospital, Stuttgart

${ }^{6}$ Medizinische Klinik I, Abteilung für Pneumologie, Klinikum Großhadern, München

${ }^{7}$ Klinik für Radiologische Diagnostik, Universität Tübingen

durch die hohen Sauerstoffspannungen bedingt, denen das Lungengewebe ständig ausgesetzt ist. In diesem Zusammenhang konnte experimentell gezeigt werden, dass die Ursache für die Toxizität des Sauerstoffs eine erhöhte endogene, zelluläre ROS-Produktion ist [15]. Die außerordentlich hohe Dichte an alveolären und interstitiellen Leukozyten, die als Teil des pulmonalen Defence-Mechanismus gegen aerolisierte Fremdkörper unerlässlich sind, stellt zudem ein beachtliches Reservoir für die Freisetzung von Zytokinen und Wachstumsfaktoren dar.

Für die Evaluation und diagnostische Einschätzung therapieassoziierter, pulmonaler Nebenwirkungen stehen routinemäßig radiologische Verfahren $[16,17,18]$ und die Messung von Lungenfunktionsparametern $[19,20]$ im Vordergrund. Diese Methoden sind jedoch in der Diagnose von Frühveränderungen weder sensitiv noch spezifisch. Umgekehrt ist die bronchoalveoläre Lavage [21,22] als diagnostische Methode nicht allgemein verfügbar oder in diesem Zusammenhang nicht ausreichend etabliert. In der Regel sind somit die klinisch-diagnostischen Erfahrungen in der Frühphase der Erkrankung für die Einschätzung des Ausmaßes der drohenden Folgezustände unzureichend. Andererseits würden standardisierte Diagnose- und Analysealgorithmen therapieassoziierter, pulmonaler Veränderungen eine individuelle, optimierte Dosisanpassung der zytoreduktiven Therapie ermöglichen $[17,23,24]$.

Die vorliegende Übersichtsarbeit möchte die wesentlichen pathogenetische Mechanismen radikalbedingter Lungenschädigungen unter Radio- wie unter Chemotherapie darstellen, sowie invasive und nichtinvasive Verfahren zur Diagnostik diskutieren. Hierdurch sollen nicht zuletzt zukünftige Forschungsarbeiten auf diesem Gebiet ermutigende Anstöße finden.

\section{Pulmonale Nebenwirkungen der Radio-Chemotherapie}

Sowohl nach pulmonaler Strahlentherapie $[25,26,27]$ wie nach systemischer Chemotherapie $[17,28,29,30]$ wird eine hohe Manifestationsrate pulmonaler Nebenwirkungen beobachtet. Bei kombinierter Anwendung beider Modalitäten sind diese Effekte gehäuft und deren Vorhersagbarkeit weiter beeinträchtigt $[6,7,8]$. 
Nach Einwirkung ionisierender Strahlung auf Lungengewebe können zwei verschiedene Nebenwirkungsmechanismen unterschieden werden:

1. Die so genannte klassische Strahlenpneumonitis [31] zeigt eine Schwellendosis und eine charakteristische sigmoide Dosis-Wirkungs-Beziehung. Dabei beschränkt sich die entzündliche Reaktion auf das bestrahlte Lungenvolumen und wird von einer mehr oder weniger starken Fibrosierung gefolgt. Ursächlich werden für diese Reaktion reaktive Sauerstoffspezies verantwortlich gemacht.

2. Die sporadische Strahlenpneumonitis [31,32] folgt keiner eindeutigen Dosis-Wirkungs-Beziehung. Ursache dieser Reaktion ist möglicherweise eine endogene Antigenbelastung, die im Rahmen der massiven Gewebsschädigung auftritt [31]. Hier wird eine generalisierte, lymphozytäre Entzündung mit vergleichsweise geringer Tendenz zur Fibrosierung beobachtet.

Schwere Verläufe nach thorakaler Strahlentherapie zeigen eine massive Diffusionseinschränkung $[19,20]$ und Veränderungen des Verhältnisses von Ventilation und Perfusion (Mismatch) [33]. Dabei führen Mikroatelektasen und eine zunehmende Ansammlung extrazellulärer Matrixproteine (ECM) in den Alveolen und im Interstitium zu funktionslosen terminalen Ventilationsräumen. Die Zunahme des ventilatorischen Totraums und des intrapulmonalen Shunt-Volumens verstärken die resultierende Hypoxämie weiter.

Viele Substanzen, die in der Therapie solider Tumoren sowie bei hämatologischen Erkrankungen verwendet werden, sind potenziell lungentoxisch $[23,24]$. Die durch sie induzierten Überempfindlichkeitspneumonitiden sind durch ein lymphozytäres Infiltrat des Lungeninterstitiums gekennzeichnet [34]. Obwohl relativ häufig zu beobachten, liegen bis heute vergleichsweise wenige Erkenntnisse über Ursachen und Mechanismen dieser Reaktion vor. In vielen Fällen klingen die Beschwerden nach Absetzen des Zytostatikums zügig ab. Durch die systemische Anwendung von Kortikosteroiden kann der Verlauf oftmals günstig beeinflusst werden.

Für die nach längeren Latenzzeiten auftretenden, chemotherapieassoziierten, so genannten Late-Onset-Pneumonitiden werden Imbalancen zwischen Oxidantien und Antioxidantien als Ursache diskutiert [17]. Dieses Symptombild der Pneumonitis ist potenziell lebensbedrohlich für den Patienten. Trotz sofortigen Absetzens der Noxen und des systemischen Einsatzes von Kortikosteroiden kann sich das Befinden des Patienten kontinuierlich und dramatisch verschlechtern $[17,35,36]$, wobei morphologische Strukturveränderungen mit Kollaps der distalen Atemwege und Ausbildung von Mikroatelektasen [37] sowie eine ausgeprägte interstitielle Fibrosierung beobachtet werden [17].

Eine relativ seltene Begleiterscheinung der Radio-Chemotherapie ist die Bronchiolitis obliterans [24]; sie stellt sich als polyploide Bindegewebsanreicherung in den Lumina der kleinsten Luftwege mit entzündlichen Veränderungen der umgebenden Luftwege dar [37]. Zum medikamenteninduzierten, nichtkardiogenen Lungenödem (capillary leak syndrome) [38], einem ebenfalls seltenen Nebenwirkungsbild, liegen nur wenige Daten vor. Hier geht man vor einer massiven Schädigung der pulmonalen Kapillarendothelien als Ursache aus [24].
Nach Radio-Chemotherapie können sich somit vielfältige Lungenschäden manifestieren, die entscheidende Bedeutung für die Prognose des Patienten sowie das weitere therapeutische Prozedere haben. Hier weisen sowohl die zytostatika- als auch die strahlungsinduzierten Reaktionen im Hinblick auf ihre klinische Symptomatik und ihre morphologischen Veränderungen große Ähnlichkeiten auf. Bedenkt man die vergleichbare Ätiologie, bei der ROS die entscheidende Rolle spielten, so dürften, neben der Gruppe der zellzyklusabhängigen radiosensibilisierenden Substanzen, bestimmte Zytostatika auf Grund additiver pro-oxidativer Effekte als Radiosensitiser fungieren. Für Bleomycin [6], Cyclophosphamid [8] und Adramycin [7] liegen hierzu zahlreiche klinische Beobachtungen vor. Die zunehmende klinische Erfahrung weist überdies darauf hin, dass die Mehrzahl der heute eingesetzten Chemotherapien ein ähnliches, die oxidative Potenz der Strahlentherapie weiter verstärkendes Verhalten zeigen [39].

\section{Klinisches Bild und Diagnostik}

Das klinische Bild der pulmonalen Nebenwirkungen während zytoreduktiver Therapie ist weitgehend unspezifisch. So fallen die Patienten zunächst durch Reizhusten, Fieber und Dyspnoe auf [24]. In schweren Fällen können Zyanose, Cor pulmonale und Rechtsherzversagen zum Tod führen [17]. Wegen der Unspezifität der Symptome und großer interindividueller Unterschiede in der Präsentation ist die Diagnose weitgehend von ärztlicher Erfahrung sowie radiologischer und lungenfunktionsanalytischer Methodik abhängig.

Nach Bestrahlung der Lunge mit hohen Dosen entwickeln die Patienten typischerweise nach 6-12 Wochen klinische Symptome [16]. Husten, Fieber und Abgeschlagenheit klingen in den meisten Fällen spontan ab, während einige Patienten eine progressive Lungenfibrosierung innerhalb der nächsten 6-12 Monate erleiden. Abhängig vom verwendeten zytoreduktiven Therapieschema vergehen bei alleiniger Chemotherapie von Behandlungsbeginn bis zur Manifestation pulmonaler Symptome ein bis zwei Monate [23,24], wobei etwa für Cyclophosphamid auch Extreme von mehreren Jahren berichtet wurden [17]. Dabei ist die Symptomatik ähnlich der der strahlungsinduzierten Lungenschädigungen.

Thorax-Röntgen und Thorax-CT zeigen je nach Schweregrad etwas inhomogene, milchglasige Trübungen bis hin zu dichten, retikulären und nodulären, entzündungs- und fibrosebedingten Infiltraten mit Pleuraverdickungen [16]. Derartige radiologische Befunde können jedoch erst in einer relativ fortgeschrittenen Phase des Krankheitsverlaufs erhoben werden, wenn der entzündliche Prozess bereits ein florides Stadium erreicht oder durchschritten hat [40] und zumeist nicht mehr reversibel ist [24]. Lungenfunktionsanalysen, die im Sinne der morphologischen Veränderungen eine beeinträchtigte Diffusionskapazität und eine restriktive Ventilationsstörung anzeigen [19,20], sind in der Frühphase der pulmonalen Veränderungen bzw. oxidativen Belastung weder sensitiv noch spezifisch genug [33].

Die Lungenperipherie entspricht einer Gasaustauschfläche von mehr als einhundert Quadratmetern. Die Alveolen als kleinste Untereinheiten der terminalen Luftwege werden von Typ-1- und Typ-2-Pneumozyten ausgekleidet. Typ-1-Pneumozyten (95\%), sind vollständig ausdifferenzierte Zellen mit 
großer Sensibilität gegenüber endogenen wie exogenen Schädigungen und nur geringem regenerativen Potential. Typ-2Pneumozyten, Stammzellen der Typ-1-Zellen, weisen dagegen ein vergleichsweise geringes Verletzungspotential gegenüber Stressfaktoren auf, können aber durch überschwellige Stimuli ebenfalls zur Proliferation angeregt werden. Typ-2Pneumozyten sind darüber hinaus maßgeblich an der Surfactant-Produktion beteiligt und besitzen die Fähigkeit zur Sekretion von extrazellulärer Matrix [41].

Unter physiologischen Bedingungen wird die Begrenzung zwischen terminalen Ventilationsräumen und Erythrozyten lediglich durch das Kapillarendothel, eine gemeinsame Basalmembran und das Alveolarepithel gebildet. Kapillarendothelien, wie Typ-1-Pneumozyten, sind anfällig für zahlreiche schädigende Einflüsse und ebenfalls zur Proliferation fähig [37]. Fibroblasten synthetisieren den weitaus größten Anteil der extrazellulären Matrix. Ihre ohnehin schon große Anzahl im Interstitium kann nach Lungenschädigungen nochmals deutlich ansteigen. Zelluläre Produkte der Fibroblasten sind unter anderem Kollagene des Typs I, III, IV, V und VI sowie Fibronektin, Laminin und Proteoglykane, die in verschiedenen Zusammensetzungen die Binde- und Stützgewebe bilden.

Neben Fibroblasten finden sich auch Makrophagen, Mastzellen, Lymphozyten und Plasmazellen im Interstitium [42]. Teile dieser Populationen verlassen das Interstitium, treten in die Ventilationsräume über und sind nun, zusammen mit anderen gelösten Bestandteilen, durch die bronchoalveoläre Lavage (BAL) gewinnbar. So ermöglicht die BAL auch Rückschlüsse hinsichtlich des Zustandes des Interstitiums [43]. Obwohl bisher als standardisiertes Diagnostikum von radiochemotherapie-induzierten, pulmonalen Nebenwirkungen nicht eingesetzt, könnte sie ein nützliches Instrument zur frühen Diagnose und zum Monitoring dieser pulmonalen Veränderungen werden.

\section{Antioxidative Strategien}

Die fortlaufende Produktion von ROS ist ein elementares Merkmal aeroben Lebens. Um Biomoleküle vor deren Einwirkung zu schützen, haben Organismen leistungsfähige antioxidative Abwehrmechanismen entwickelt. Die Anfälligkeit für oxidative Schäden zeigt interindividuelle Unterschiede [44], was möglicherweise eine Folge verschiedenartig etablierter antioxidativer Mechanismen ist [45].

Bei der Entgiftung der während des physiologischen Zellstoffwechsels anfallenden erheblichen Mengen an ROS kommt insbesondere den enyzmatischen Abwehrmechanismen große Bedeutung zu. Superoxid-Radikale $\left(\mathrm{O}_{2}{ }^{*}-\right)$ können durch verschiedene Superoxiddismutasen in Wasserstoffperoxid $\left(\mathrm{H}_{2} \mathrm{O}_{2}\right)$ überführt werden. $\mathrm{H}_{2} \mathrm{O}_{2}$ wird weiter umgewandelt in Wasser, eine Reaktion, die durch Katalasen und Glutathionperoxidasen katalysiert wird. Glutathion, ein ubiquitäres Tripeptid, kann Verbindungen mit einer Reihe von elektrophilen Substanzen entweder enzymatisch oder nichtenzymatisch eingehen. Dabei entstehendes Glutathiondisulfid (GSSG) wird durch NADPH-abhängige Glutathionreduktasen wieder in die ursprüngliche Form überführt.

Die Vitamine $\alpha$-Tocopherol und Askorbinsäure wirken synergistisch bei der Entgiftung von Oxidantien. Das lipidlösliche
$\alpha$-Tocopherol verbindet sich bevorzugt mit Radikalen, die während radikalbedingter Lipidperoxidationen anfallen. Es ist somit in der Lage, das Ausmaß dieser Kettenreaktionen zu begrenzen. Nach Wanderung zur Oberfläche der Lipidmembranen kann das entstandene Tocopherol-Radikal durch Askorbinsäure neutralisiert werden, die selbst in das relativ stabile Semidehydroaskorbat überführt wird. Askorbinsäure ist als potente antioxidative Substanz auch zur Entgiftung einer Reihe anderer reaktiver Verbindungen fähig.

Um die Entstehung von ROS zu verhindern, werden Übergangsmetallionen wie Eisen und Kupfer konsequent in gebundenem Zustand transportiert und gespeichert. Über die Fenton-Reaktion würde, in Anwesenheit freier Metallionen, ansonsten vorhandenes $\mathrm{H}_{2} \mathrm{O}_{2}$ in Hydroxylradikale $\left(\mathrm{OH}^{*}\right)$ umwandelt werden. Der extrem niedrige Gehalt intra- wie extrazellulärer Flüssigkeiten an freiem Eisen und Kupfer wird durch metallbindende Proteine wie Transferrin, Ferritin und Coeruloplasmin ermöglicht. Sie fungieren somit als indirekte Antioxidantien.

Auch Plasmaproteine und Proteine anderer Kompartimente können, dank ihres Gehalts an Sulfhydrylgruppen, als potente Antioxidantien fungieren. So ist im Blutplasma neben Harnsäure und Askorbinsäure Albumin die bedeutendste antioxidative Substanz.

Da ROS innerhalb der Zellstruktur vielfältige Schäden verursachen können, verfügen pro- und eukaryote Zellen über leistungsfähige Adaptionsmechanismen. Werden menschliche Lymphozyten in vitro oder in vivo niedrigen Dosen ionisierender Strahlung ausgesetzt, werden nachfolgende, hochdosierte Bestrahlungen besser toleriert $[46,47]$. Andere Einflüsse wie Hyperoxie, Oxidantien, Hyperthermie, Endotoxin und Ischämie-Reperfusion, die mit erhöhter ROS-Belastung assoziiert sind, können ebenfalls eine solche adaptive Antwort (AW) auslösen $[48,49,50,51]$, wobei Ausmaß und Spezifität der Stressantwort von Zelltyp und Stimulus abhängig sind. Weiterhin wurde beobachtet, dass einer der Stimuli zu gesteigerter Widerstandsfähigkeit auch gegenüber einem anderen Stimulus führen kann $[50,52]$.

Die adaptive Antwort besteht, nach dem gegenwärtigen Stand des Wissens, aus einem komplexen Zusammenspiel zahlreicher Komponenten. Dabei ist eine adaptive Antwort von einer intakten Proteinsynthese abhängig [47]. Neben effizienteren DNA-Reperatur-Mechanismen [53], Funktionserhalt oder -erhöhung antioxidativ wirksamer Enzyme [54,55] und Inhibition von proinflammatorischen Non-Stress-Proteinen wird insbesondere die verstärkte Expression einer heterogenen Gruppe von protektiv und anti-apoptotisch [56] wirksamen Hitzeschockproteinen (HSP) für diese Anpassungsreaktionen verantwortlich gemacht. In Versuchen mit selektiv transfizierten Zellen $(55,57,58]$ wurde es möglich, einzelnen Elemente der adaptiven Antwort isoliert auf ihre relative Wertigkeit zu untersuchen. Die Gruppe der HSP besteht aus verschiedenen Proteinen von 8-110 kDa. $\mathrm{Zu}$ ihnen gehören Proteine, die bereits im Zusammenhang mit anderen Prozessen beschrieben wurden und deren Expression unter zellulärem Stress erst später erkannt wurde. Am besten charakterisiert sind die HSP70-Familien und die Hämoxygenase (HO-1, $32 \mathrm{kDa}$ ), die den ersten Schritt des Hämabbaus katalysiert. 
Einige HSP fungieren als molekulare Chaperone. Sie sind residente Bestandteile des endoplasmatischen Retikulums und erfüllen wichtige Aufgaben bei der Reifung und Faltung von Proteinen, bevor diese über den Golgi-Apparat auf die jeweiligen Zellkompartimente verteilt werden. So ist z.B. HSP47 ein spezifischer Chaperon für Prokollagen [59]. Darüber hinaus wird es unter pro-oxidativen Einflüssen, z.B. Hyperthermie [60] und Bleomycinexposition [61], verstärkt exprimiert. Stets wird jedoch eine simultane Unter- und Überexpressionen von HSP47 und Kollagenen beobachtet [61, zusammengefasst in 59]. So konnte bei selektiver Hemmung der HSP47-Expression auch eine erheblich herabgesetzte Kollagensynthese beobachtet werden [62]. Dies lässt die Vermutung zu, dass die zelluläre Stressantwort Voraussetzung für eine überschießende Kollagensynthese ist.

In kürzlich durchgeführten Untersuchungen konnte beobachtet werden, dass die dargestellten stressbedingten Veränderungen im zellulären Proteinexpressionsmuster direkt zur Abnahme ROS-bedingter Schäden führen können. So zog die Überexpression von HSP25 in murinen Fibroblastenzelllinien eine erhebliche Reduktion ROS-induzierter DNA-Schädigungen nach sich [57]. Für diesen protektiven Effekt konnte unter anderem eine relative Steigerung der intrazellulären Glutathion (GSH)-Konzentrationen verantwortlich gemacht werden [55]. Nach HSP70-Transfektion und folgender hyperoxischer Belastung humaner Lungenadenokarzinomzellen konnte eine herabgesetzte Intensität der Lipidperoxidation und eine Verminderung des zellulären ATP-Verlustes beobachtet werden [58]. Der Mechanismus der herabgesetzten zellulären ROS-Genese nach HSP70-Expression scheint auf einen Schutz der mitochondrialen Integrität zurückgeführt werden zu können. Hier werden im Rahmen physiologischer Oxidationsprozesse ohnehin große Mengen an ROS generiert [9]. Nach erfolgter adapativer Antwort und nachfolgender experimenteller $\mathrm{H}_{2} \mathrm{O}_{2}$-Belastung konnte in einer humanen prämonozytischen Zelllinie gezeigt werden, dass die mitochondrialen Membranpotentiale, im Gegensatz zu Zellen ohne adaptive Antwort, nahezu konstant bleiben [52]. Auch die vermehrte Expression kleinerer HSP (25/27) trägt dazu bei, unter Einfluss von ROS die strukturelle Mitochondrienintegrität nahezu vollständig aufrechtzuerhalten [55].

Unklarheit herrscht über die Wertigkeit der HSP-Expression im Lungengewebe. Bei gesunden Nichtrauchern konnten HSP72 und HSP90 in Zylinderepithelien der oberen Atemwege in relativ großen Mengen nachgewiesen werden [63]. Weiter peripher, bei Überwiegen von einschichtigen, kuboidalen Zellen, wurden diese beiden HSP nicht gefunden. So waren auch in Typ-1- und Typ-2-Pneumozyten HSP72 und HSP90 nicht darstellbar, ebenso wie in allen anderen pulmonalen Parenchym- und Stromazellen.

Während in einer Reihe extrapulmonaler Zellen HSP70 durch Endotoxin, Hyperthermie und Oxidantien induzierbar war [49,51,64], konnte durch Endotoxin in Endothelien der Pulmonalarterien keine HSP70-Expression hervorgerufen werden [65]. In trachealen Epithelien von Meerschweinchen waren durch Ozon und $\mathrm{H}_{2} \mathrm{O}_{2}$ keine $\mathrm{HSP}$ induzierbar, und hyperthermieinduzierte HSP schützten die Zellen nicht vor ozonbedingter Schädigung [48]. In Untersuchungen an Rauchern, die unter permanenter oxidativer Belastung stehen, konnte, verglichen mit Nichtrauchern, keine veränderte HSP-Expres- sion im Lungengewebe beobachtet werden [63]. Vieles deutet somit auf noch nicht erkannte Mechanismen im Expressionsmuster der HSP in pulmonalen Zellen sowie bei deren protektiver Rolle hin.

Die Mehrheit der alveolären und interstitiellen Makrophagen exprimiert bereits unter basalen Bedingungen HSP63, 72, 90 [63]. Unter Einfluss von Ozon [66] sowie bei Patienten, die unter Asthma [67] und ARDS litten [68], wiesen die alveolären Makrophagen eine signifikant gesteigerte HSP-Expression auf. Das Ausmaß der Expression von HSP durch diese Zellen sowie spezifische Charakteristika der Stressantwort könnten somit als Marker der oxidativen Lungenbelastung dienen. (Diese Fragestellung wird derzeit im Rahmen einer Studie von uns an Lavagen von Patienten mit Bronchialkarzinom unter RadioChemotherapie untersucht.)

\section{Zell- und Gewebsveränderungen}

Die morphologischen Veränderungen nach Bestrahlung der Lunge und nach Behandlung mit zytotoxischen Substanzen sind durch Degeneration, Entzündung und Reparatur gekennzeichnet. Bleomycin wird seit Jahren als Modellsubstanz für oxidative Lungenschädigungen verwendet. Für andere, in der Tumortherapie verwendete Medikamente liegen hingegen vergleichsweise wenige Erfahrungen vor. Verwendet wurden für derartige Experimente vor allem Ratten [33,42,69,70,71], Mäuse [72,73], Schafe [74] und Hunde [75,76]. Eine standardisierte Methode der Bleomycinapplikation konnte sich bisher nicht durchsetzen. So repräsentieren intratracheale, intravenöse sowie intraperitoneale Gaben möglicherweise unterschiedliche Schädigungs- und Reparaturmuster. Nach intraperitonealer und intratrachealer Einbringung von Bleomycin wurde neben einem interstitiellen Ödem eine Ablösung endothelialer Zellen von den Basalmembranen beobachtet $[69,73]$.

Nach Applikation hoher Bleomycin-Dosen wurden stellenweise Abnahmen des Alveolardurchmessers als morphologisches Korrelat einer Fibrosierung des Lungengewebes festgestellt [72,73]. Auch nach länger andauernder Applikation hoher Ifosfamid-Dosen sind morphologische pulmonale Veränderungen beschrieben worden. Hier erschienen die Lungen nach etwa 2 Wochen insgesamt dunkel, verhärtet und verstärkt blutgefüllt [75].

Etwa acht Wochen nach Beginn einer thorakalen Bestrahlung lassen sich erste makroskopische Veränderungen aufzeigen. Hier wurden fleckige Aufhellungen des Lungenparenchyms beschrieben. Später erscheint das Gewebe insgesamt verhärtet und geschrumpft [70]. Bereits etwa zwei Wochen nach Bestrahlung ist der Wassergehalt des Lungengewebes deutlich erhöht [71]. Dabei sind sowohl interstitielle Strukturen wie intraalveoläre Räume ödematös verändert [74]. Bereits innerhalb der ersten Wochen nach Bestrahlungsbeginn steigt die Leukozytendichte in den pulmonalen Kapillaren. Einige Zeit später treten Großteile dieser Zellpopulation in das Interstitium über, so dass die Leukozytenzahl hier ebenfalls ansteigt [71]. Bei der Auswertung der Gesamt- und Differentialzellzahlen in der Epithelial lining fluid (ELF) und im Interstitium stellen sich große Unterschiede bezüglich untersuchter Tierspezies, Dosis und Zeitintervall dar. Das jeweilige Ansteigen der Zelldichte wird durch Alveolarmakrophagen, 
Lymphozyten und polymorphonukleäre Zellen (PMN) getragen [71]. Ähnliche Veränderungen der Leukozytendichte wurden nach intratrachealer Bleomycin-Gabe beschrieben [69]. Dabei normalisierte sich der PMN-Anteil der ELFPopulationen etwa nach vier [69] bis acht [76] Wochen, in anderen Beobachtungen auch erst nach längerer Zeit [76].

Nach thorakaler Bestrahlung sowie nach Bleomycin-Behandlung werden Bestandteile der extrazellulären Matrix innerhalb des Interstitiums abgelagert, so dass sich dessen Dicke deutlich erhöht $[69,71,73]$. Interstitielle Fibrosierungen können auch durch intraalveoläre Ablagerungen vorgetäuscht werden [zusammengefasst in 37]: Durch die massive Epithelschädigung und stellenweise nunmehr zelllosen Basalmembranen wird die Entstehung eines fibrinreichen Exsudates in den terminalen Ventilationsräumen begünstigt. Auch im Rahmen einer Pneumonitis steigt lokal die Permeabilität, und proteinreiches Exsudat gelangt in alveoläre Räume [21]. In der Folge können diese Exsudate organisiert und reepithelialisiert werden und nun als fibrotisch verdicktes Interstitium imponieren [37]. Im Experiment wurden auch pulmonales Epithel und Endothel bestrahlter Tiere verdickt vorgefunden [42].

Typ-1- und Typ-2-Pneumozyten zeigen hierbei früh degenerative Veränderungen, wobei insbesondere Typ-1-Zellen nach Bestrahlung [42] und Zytostatikagabe [73,75] zahlenmäßig stark vermindert sind. Die freiliegenden Basalmembranen erscheinen geschwollen und verdickt. Einige Monate nach Bestrahlung sind die Typ-1-Zellen in ihrer Zahl nochmals vermindert [42]. Typ-2-Pneumozyten sind fokal hyperplasiert [74] und zeigen stark vergrößerte Zellvolumina [42]. Im Epithelgefüge tauchen kubische Zellen auf, die noch nicht vollständig zu Typ-1-Pneumozyten ausdifferenzierte Abkömmlinge von Typ-2-Zellen sind [73]. Diese Zellen kleiden nun eine wachsende Zahl von Alveolen aus. In Versuchen mit Bleomycin begann der Repopulationsvorgang dabei im Bereich der Bronchioli und setzte sich nach peripher fort [72].

Im Blut anflutende Substanzen schädigen in erster Linie das Epithel, während ionisierende Strahlung bevorzugt die Kapillarendothelien beeinträchtigt [37]. Drei Monate nach Bestrahlung ist auch ihre Zahl herabgesetzt [42]. Ein beachtlicher Anteil der alveolären Kapillaren ist nachhaltig durch mononukleäre Zellen, Fibrin und Kollagen [74] verstopft. Dadurch ist die Perfusion innerhalb bestrahlter Lungenfelder stark herabgesetzt [33].

\section{Bildung von ROS}

Während einer Radio- oder Chemotherapie entstehen über verschiedene Mechanismen große Mengen an ROS, die bei der Genese einer Pneumonitis oder Lungenfibrose eine wesentliche Rolle spielen. Wirkt ionisierende Strahlung auf wasserhaltige, biologische Gewebe ein, wird eine der kovalenten Bindungen des Wassers homolytisch gespalten. Dabei entstehen ein Wasserstoffradikal $\left(\mathrm{H}^{*}\right)$ und ein hochreaktives Hydroxylradikal $\left(\mathrm{OH}^{*}\right)$ [9], die nach gegenwärtigem Stand des Wissens die Ursache sowohl der Strahlenwirkung als auch der Toxizität sind. Für eine Reihe zytoreduktiver Substanzen können die zytoreduktive Wirkung und die Nebenwirkungen ebenfalls auf die Entstehung freier Radikale zurückgeführt werden. Zu ihnen gehören Bleomycin, Cyclophosphamid und Ifosfamid, Adramycin, Etoposid und Mitomycin. Dabei kann gerade die Lungenschädigung substanztypisch sein (Bleomycin) oder andere Organe bei der Manifestation von Nebenwirkungen dominieren (Myokardschädigungen durch Adriamycin).

Die lungenschädigenden Effekte von Bleomycin sind bereits seit Jahrzehnten bekannt. Das zur Familie der Antibiotika zählende Zytostatikum neigt zur Bildung von $\mathrm{O}_{2}$-Fe(II)-Bleomycin-Komplexen, die wiederum zur Entstehung von reaktionsfreudigen Hydroxylradikalen führen [77]. So wurde nachgewiesen, dass in Anwesenheit von Bleomycin Fettsäuren in ihrer Struktur verändert und potente Oxidantien freigesetzt werden [78]. Eine wichtige Ursache für die lungenschädigende Wirkung von Bleomycin ist dabei die relativ niedrige Aktivität der Bleomycin-Hydrolase, eines katabolisierenden Enzmys, im Lungenparenchym und die daraus resultierenden hohen lokalen Bleomycin-Konzentrationen.

Kürzlich durchgeführte Experimente an Alveolarmakrophagen und peripheren Monozyten von bleomycinbehandelten Tieren zeigen, dass diese Population eine erhöhte Bereitschaft zur Freisetzung von Superoxid-Radikalen hat, und lassen vermuten, dass diese Zellen möglicherweise direkte Zielzellen der Substanz sind [79]. Im Gegensatz hierzu war in einem anderen Versuch die Superoxid-Radikal-Produktion bei in vitro bleomycinbehandelten humanen Alveolarmakrophagen erheblich herabgesetzt [80], was zu Spekulationen Anlass gibt, dass die erhöhte Radikal-Genese im ersten Experiment eher eine indirekte Folge der Bleomycingabe gewesen ist.

Cyclophosphamid und Ifosfamid besitzen strukturelle Ähnlichkeiten und qualitativ gleiche Transformationswege. Beide können zum korrespondierenden 4-Hydroxymetaboliten oxidiert werden und reagieren letztendlich $\mathrm{zu}$ Acrolein und Phosphoramidverbindungen [81]. Während dieses Abbauweges entstehende Metabolite werden für die Lungentoxizität verantwortlich gemacht, da Ifosfamid, das größere Affinität zu einem anderen Metabolisierungsmechanismus hat (Oxidation zu Dechlorethyl-Ifosfamid und Chloroacetaldehyd), geringere pulmonale Toxizität aufweist als Cyclosphosphamid. Es ist unklar, ob beide Alkylantien oder ihre Metaboliten direkt pro-oxidativ wirksam werden können, oder ob diese Effekte indirekt durch Erniedrigung der Glutathion-Pools zustande kommen [82]. In diesem Zusammenhang konnte gezeigt werden, dass Cyclophosphamid den Glutathiongehalt der Lunge [83] und Ifosfamid den von Blutlymphozyten herabsetzt [84]. In weiteren Untersuchungen wurde beobachtet, dass Acrolein den GSH-Gehalt in der Leber absenkt [82], jedoch den Gehalt in der Lunge nicht beeinflusst [83].

Anthrazykline allein sind in den seltensten Fällen lungentoxisch. Sie sind jedoch in der Lage, die Toxizität einer Bestrahlung zu verstärken. Freie Radikale entstehen, wenn $\mathrm{Fe}^{3+}$ oder $\mathrm{Cu}^{2+}$ bei Bindung durch Adriamycin reduziert werden. In Anwesenheit der reduzierten Metallionen und von $\mathrm{O}_{2}$ können dann Hydroxlradikale generiert werden [85]. Experimentell konnte die enge Assoziation zwischen der Fähigkeit zur $\mathrm{Fe}^{3+}$-Reduktion und der Radikalentstehung gezeigt werden [86]. Während der Aktivierung von Adriamycin kann dieses ein Elektron erhalten, um so zum SemiquinonRadikal zu werden $[85,87]$, das relativ instabil ist und in Anwesenheit von Sauerstoff zur Bildung von SuperoxidRadikalen führen kann. 
Wie Adriamycin kann auch Mitomycin durch Reduktion aktiviert werden. Dabei entsteht ein Semiquinon-Radikal oder das korrespondierende Hydroquinon [88]. Unter hypoxischen Bedingungen dominiert jedoch der Metabolismus zum Semiquinon. Die Semiquinone können als potente Alkylantien fungieren. Je nach Anwesenheit von Sauerstoff werden diese zügig autoxidiert und generieren dabei Superoxid-Radikale und Wasserstoffperoxid. Somit fällt die Konzentration des Semiquinons $a b$, und der Grad der DNA-Alkylation geht infolgedessen zurück. Ist der Sauerstoffpartialdruck gering, häuft sich das Semiquinon an und reagiert mit $\mathrm{H}_{2} \mathrm{O}_{2}$, um Hydroxylradikale zu generieren. Diese Reaktion ist unabhängig von der Anwesenheit katalytischer Metallionen.

\section{ROS und Fibrose}

Wie aus einer wachsenden Anzahl experimenteller Veröffentlichungen hervorgeht, kann ein Missverhältnis von Oxidantien und Antioxidantien zur verstärkten Ablagerung von Komponenten der extrazellulären Matrix (Kollagene, Fibronektin, Proteoglykane) führen $[12,89]$. Dies kann neben der Lungenfibrose auch bei einer Reihe von Erkrankungen mit verstärkter Fibrogenese (neurodegenerative Erkrankungen, M. Wilson, Hämochromatose, zystische Fibrose, Leberzirrhose, Atherosklerose) beobachtet werden.

\section{Schädigung und Entzündung}

Der Angriff von ROS auf zelluläre Komponenten kann zu strukturellen und funktionellen Veränderungen von Membranlipiden, Proteinen und DNA führen [10]. Die überwiegende Anzahl der DNA-Doppelstrangbrüche kann suffizient repariert werden, während die verbleibenden Schäden zu sofortigem oder prolongiertem apoptotischen Interphasezelltod oder zum postmitotischen Zelltod führen können [90]. Ist der zelluläre ATP-Gehalt, wie unter oxidativem Stress, deutlich erniedrigt [91], überwiegt die nekrotische Degeneration mit nachfolgender Entzündung [92]. Membrantransportproteine können durch freie Radikale in ihrer Funktion beeinträchtigt werden. Das führt unter anderem zu gesteigerten intrazellulären $\mathrm{Ca}^{2+}$-Konzentrationen mit Aktivierung von Phospholipasen, Endonukleasen und Proteasen und infolgedessen zu Veränderungen am Zytoskelett [91].

Die frühe Phase nach Lungenschädigung wird durch ortsständige Zellen wie Alveolarmakrophagen, Fibroblasten, Endothelien und Epithelien vermittelt. Alveolarmakrophagen sind in der Lage, verschiedene Zytokine und Wachstumsfaktoren zu sezernieren, u. a. TNF- $\alpha$, IL-6, IL-8 und IL-1.

IL-1 besitzt erhebliche Bedeutung bei der T-Zellaktivierung [93] wie bei der Induktion weiterer Elemente der Zytokinkaskade und scheint ein wichtiges Element der Entzündungsinitiation zu sein. Die relativ geringe Fähigkeit der Alveolarmakrophagen, ihre IL-1 $\beta$-Sekretion zu steigern $[94,95]$ setzt möglicherweise einen Influx von peripheren Blutmonozyten voraus, um signifikante IL-1 $\beta$-Spiegel zu erreichen und weitere Glieder der Mediatorenkette zu aktivieren [13]. So konnte nach In-vitro-Bestrahlung von Alveolarmakrophagen lediglich ein limitiertes Vermögen zur IL-1-Sekretion beobachtet werden [96]. In Tiermodellen zur Lungenfibrose wurde deutlich, dass erst nach einer Latenzphase von etwa zwei Wochen die Sekretion dieses Zytokins erheblich anstieg [40].
Der Influx von neutrophilen Granulozyten wird wesentlich von IL-8, IL-1, TNF, aktiviertem Komplement und als Folge der Lipidperoxidation entstandenem 4-Hydroxynonenal (HNE) beeinflusst. Das ist auch teilweise Folge der IL-1- und TNFgetriggerten Expression von Adhäsionsmolekülen (ICAM-1 = intracellular cell adhesion molecule-1, ELAM-1 = endothelial leukocyte adhesion molecule-1). Sie steigern die Adhärenz der Leukozyten an endotheliale Zellen und unterstützen deren Diapedese. Neutrophile Granulozyten sind in der Lage, aggressive ROS, die bei der Bekämpfung von Mikroorganismen unerlässlich sind, in großen Mengen an ihre Umgebung abzugeben.

Die Seitenketten von Membranphospholipiden sind besonders anfällig für radikalbedingte Veränderungen. In typischen Kettenreaktionen kann ein $\mathrm{OH}^{*}$ hier zur Entstehung hunderter von Peroxiden sowie Aldehydverbindungen wie Malonaldehyd (MDA) und HNE führen $[9,12]$. In Versuchen mit kultivierten Zellen erwies sich HNE als potenter Verstärker der Kollagen-I-Synthese [97]. Außerdem sind HNE und einige homologe Aldehyde in der Lage, chemotaktisch auf neutrophile Granulozyten zu wirken $[98,99]$.

\section{Veränderte Transkription von Zytokinen und Wachstumsfaktoren}

Neben einer Entzündungsreaktion als Stimulus für eine massive Freisetzung von Zytokinen und Wachstumsfaktoren kann oxidativer Stress auch direkt zu Veränderungen im Proteinexpressionsmuster führen. $\mathrm{Zu}$ den unter diesen Bedingungen verändert exprimierten Proteinen zählen auch einige proinflammatorisch und proliferativ wirkende Zytokine und Wachstumsfaktoren.

Nuclear factor kappa-B (NFK-B) und das jun-fos-Heterodimer sind Transkriptionsfaktoren, die empfindlich auf geringe Schwankungen des oxido-reduktiven Status reagieren. $\mathrm{H}_{2} \mathrm{O}_{2}$ kann NFK-B aus seinem inaktiven Komplex mit der inhibitorischen Untereinheit I $\kappa-B$ freisetzen [100] und ermöglicht eine forcierte Bindung an entsprechende DNA-Promotorsequenzen. $\mathrm{H}_{2} \mathrm{O}_{2}$-Exposition steigert auch die Aktivität von c-fos und c-jun [101]. Bindungsstellen für NFK-B finden sich unter anderem in den Promotorregionen des vascular endothelial growth factor (VEGF) [102] sowie von TNF [103] und IL-6 [104]. Die Steigerung der TGF- $\alpha$-Synthese wird vermittelt durch Aktivator-Protein-1 [105]. Platelet-derived growth factor (PDGF), ein auf Bindegewebszellen stark chemotaktisch und mitogen wirkender Wachstumsfaktor, wird NFK-B-abhängig synthetisiert [106]. Für VEGF konnte die direkte, expressionsfördernde Beeinflussung durch Chemotherapieinduzierte, freie Radikale in vivo nachgewiesen werden [39].

Unter den aktivierenden Einflüssen für nukleäre Transkriptionsfaktoren finden sich wiederum einige Zytokine. So konnte kürzlich gezeigt werden, dass IL-1 $\beta$ [107] und TNF [108] die Bindungsaktivität von NFK-B steigern. Von einigen Autoren wird auch spekuliert, dass das intrazelluläre GSH/ GSSG-Gleichgewicht großen Einfluss auf die diesbezügliche Proteinsynthese haben könnte. So wird die Erniedrigung des intrazellulären GSH als Regulationsmechanismus von NFK-B diskutiert [109], ebenso als Mediator der proliferativen Effekte von $\mathrm{H}_{2} \mathrm{O}_{2}$ und $\mathrm{O}_{2}{ }^{*}-[110]$. 


\section{Entstehung von sekundärem oxidativen Stress}

Zell- und Gewebsläsionen führen, über verschiedene Mediatoren und Mechanismen, zur Entstehung von ROS. Für die meisten Erkrankungen ist dabei die massive Genese von ROS eher ein sekundäres als ein primäres Ereignis [9].

Aktivierte Phagozyten wie PMN, Monozyten und Makrophagen sezernieren $\mathrm{O}_{2}{ }^{*}-$ [111]. Darüber hinaus synthetisieren aktivierte Neutrophile HOCI [112], das, wenn auch strukturell kein freies Radikal, doch vergleichsweise hohe Reaktivität besitzt. Vieles deutet darauf hin, dass diese LeukozytenSubpopulation ein wichtiger Faktor in der Genese der Lungenfibrosierung und anderer pulmonaler Schädigungen ist $[113,114]$.

Viele der Mechanismen, die bei der sekundären Genese von ROS von Bedeutung sind, hängen eng mit dem Eisenstoffwechsel und anderen katalytisch wirksamen Metallen zusammen. Unter physiologischen Bedingungen ist der bei weitem größte Anteil des Eisens an Transferrin oder Ferritin gebunden. In Anwesenheit freien Eisens würde vorhandenes $\mathrm{H}_{2} \mathrm{O}_{2}$ unverzüglich in Hydroxylradikale umgewandelt werden [10]. Wird das physiologische Äquilibrium zu Gunsten der Oxidantien verschoben, steigt bemerkenswerterweise der Anteil ungebundenen Eisens. In der Lunge, die, wie bereits dargestellt, erheblichem oxidativen Stress ausgesetzt ist, konnten in der BALF beachtliche Mengen an pro-oxidativ wirksamem Eisen nachgewiesen werden [14]. Dies erklärt sich unter anderem dadurch, dass Superoxidradikale imstande sind, Eisen von Ferritin abzulösen [115]. Eisen, das unter Normalbedingungen in Lipidmembranen komplexgebunden ist, kann bei Untergang dieser Zellen freigesetzt werden [9]. In Anwesenheit von Wasserstoffperoxid neigen hämhaltige Proteine wie Hämoglobin und Myoglobin zu Strukturveränderungen mit Freisetzung von Eisen [116]. Bedenkt man die hohe Reaktionsbereitschaft der Hydroxylradikale, ist eine beträchtliche Radikalbelastung allein aufgrund freien Eisens denkbar.

Lungenschädigungen durch Radio- und Chemotherapie imponieren oft als großflächige Epithel-, Endothel- und Basalmembrandefekte mit diffusen Mikrohämorrhagien in den terminalen Ventilationsräumen [16]. Freies Hämoglobin kann hierbei pro-oxidativ wirksam werden und somit dem weiteren Struktur- und Funktionsverlust Vorschub leisten. In Wechselwirkungen mit endogenen Antioxidantien (GSH, Askorbinsäure) kann Oxyhämoglobin in Methämoglobin umgewandelt werden [117]. Letzteres ist imstande, mit $\mathrm{H}_{2} \mathrm{O}_{2}$ oder vorhandenen Lipidperoxiden Oxoferrylhämoglobin, seinerseits ein potentes Oxidans, sowie $\mathrm{OH}^{*}$ und Singulett-Sauerstoff hervorzubringen.

TNF und IL-1, die im Rahmen der entzündlichen Reaktion massiv sezerniert werden, können mit endothelialen Zellen in Wechselwirkung treten und so die Expression oberflächlicher Adhäsionsmoleküle fördern. So können auch PMN vor Ort vermehrt gebunden und prooxidativ wirksam werden [118]. Darüber hinaus konnte kürzlich gezeigt werden, dass diese zwei Mediatoren eine Reihe menschlicher Zellen, darunter Fibroblasten, zur forcierten Produktion von Superoxidradikalen und Wasserstoffperoxid anregen können [119].

TNF hat außerdem die wichtige Eigenschaft, endotheliale Xanthindehydrogenasen (XD) in Xanthinoxidasen (XO) zu überführen [120]. XO katalyisert die Reaktion von Xanthin zu Hypoxanthin (Abbauprodukte von ATP) und weiter zu Harnsäure, wobei $\mathrm{O}_{2}{ }^{*}$ - entsteht. Darum wird XO zuweilen auch als experimenteller Radikalbildner genutzt [89]. Auch durch Wechselwirkungen zwischen Endothelien und stimulierten Neutrophilen kann XD irreversibel und in beträchtlichem Ausmaß in XO umgewandelt werden [121]. Da die ATP-Level unter oxidativem Einfluss vermindert sind [91] und somit auch die Spiegel an Xanthin und Hypoxanthin herabgesetzt sein dürften, bleibt die Bedeutung dieses Prozesses jedoch unklar.

Eine erhöhte Belastung mit freien Radikalen kann auch nach genomischen Veränderungen und resultierendem Zelluntergang beobachtet werden. Im Rahmen des Zelltodes können Mitochondrien ihre strukturelle Integrität verlieren und größere Mengen an Elektronen verlieren, die sich mit Sauerstoff verbinden, um Superoxid-Radikale zu bilden [122].

\section{Fibroblasten als Effektorzellen}

Fibroblasten sind aktivierte mesenchymale Zellen, die maßgeblich an der Produktion der extrazellulären Matrix (ECM) beteiligt sind. Von ihnen werden Strukturproteine wie Kollagene sowie die nichtfibrillären Glykoproteine und Proteoglykane synthetisiert. Der Aktivierung von Fibroblasten kommt daher entscheidende Bedeutung bei der Genese fibrotischer Erkrankungen zu.

Fibroblasten stellen den zahlenmäßig größten zellulären Anteil im Lungeninterstitium [42]. Obwohl auch Alveolarepithelien [41] und Endothelien [123] in der Lage sind, Bindegewebskomponenten zu synthetisieren, wird der größte Anteil der Kollagen- und elastischen Fasern von Fibroblasten produziert. Dabei wird die Rate der ECM-Synthese durch Botenstoffe wie TGF- $\beta$, bFGF, PDGF, IGF-1 sowie, in einigen Fällen, IL-1 und TNF, moduliert [13].

Daneben zeichnen sich Fibroblasten auch selbst durch Sekretion von IL-1, IL-6, IL-8, IL-11, TGF- $\alpha 1$ und PDGF aus und haben so eine wichtige Funktion als Immuneffektorzellen [124]. In diesem Zusammenhang scheinen sie, in autokriner Art und Weise, wiederum promitogen und prokollagen auf sich selbst wirken zu können.

Kürzlich konnte gezeigt werden, dass Fibroblasten Superoxidradikale generieren und freisetzen [89]. Die Rate der ROSBildung wird dabei durch eine Reihe von Mediatoren (TGF- $\beta 1$, TNF, IL-1) noch gesteigert. Wie bereits erwähnt, sind moderate Konzentrationen an $\mathrm{H}_{2} \mathrm{O}_{2}$ und $\mathrm{O}_{2}{ }^{*}$ - effektive Stimulatoren für das Wachstum von Fibroblasten [89,125]. Auch in diesem Zusammenhang lässt sich ein effektiver, selbstverstärkender Mechanismus vermuten.

\section{Fibrose - Konsequenz der Pneumonitis?}

Die Frage, ob eine Pneumonitis Voraussetzung für die Entwicklung einer Lungenfibrosierung ist, wird seit jeher kontrovers diskutiert. Einige experimentelle Studien konnten die Entstehung einer Lungenfibrose ohne eine ersichtliche vorausgegangene Pneumonitis beschreiben [71,126]. Andererseits existieren zahlreiche Untersuchungen, in denen eine ausgeprägte Pneumonitis der Fibrose vorausging [42,71,73, 
127]. Einige Autoren halten die Synthese von ECM hierbei für eine gewöhnliche Folge des chronischen Entzündungsgeschehen $[31,127]$.

Pneumonitis und Fibrosierung als unerwünschte Wirkungen zytoreduktiver Therapie können beide den Tumorpatienten erheblich gefährden. Sie weisen unterschiedliche Zeitfenster und Inzidenzraten auf, wobei die Fibrose radiosensitiver ist [128]. Während die Pneumonitis eine relativ akute Folge der Lungenschädigung mit wahrscheinlicher Remission unter einer Therapieoption mit Kortikosteroiden ist, stellt die Lungenfibrose eine progressive und therapeutisch kaum zu beeinflussende Komplikation dar. Dabei sind beide Zustände Folge eines beeindruckenden Zytokin-Networkings [40].

In dieser Arbeit konnten verschiedene Mechanismen und Ursachen der Fibrosierung beleuchtet werden. So konnte nachgewiesen werden, dass die oxidative Belastung im Rahmen der Entzündung stark ansteigt (oxidativer Burst der Phagozyten, zytokinvermittelte Steigerung der zellulären ROS-Produktion, sekundäre ROS-Genese), und dass einige inflammatorische Zytokine imstande sind, promitogen $\mathrm{zu}$ wirken und die Kollagensynthese zu steigern. Für diesen Zusammenhang existieren eine Reihe experimenteller Belege $[113,129,130]$. Auch die charakteristische Reihenfolge von Pneumonitis und Fibrose lässt diese Beobachtungen plausibel erscheinen.

Einige diskutierte Mechanismen verweisen jedoch auch auf die Möglichkeit der primären ECM-Synthese, wobei eine entzündliche Reaktion als Epiphänomen auftritt, während durch Lipidmembranschädigung entstandene Alkenale und Aldehyde direkt imstande sind, die Kollagenexpression positiv $\mathrm{zu}$ beeinflussen. Auch der Influx von Leukozyten ist eine Wirkung dieser Mediatoren. Darüber hinaus können Verschiebungen des oxido-reduktiven Gleichgewichts direkt zur Aktivierung von Transkriptionsfaktoren mit nachfolgender Synthesesteigerung von proinflammatorischen und kollageninduzierenden Botenstoffen führen. Die Wertigkeit der einzelnen pathogenetischen Mechanismen ist unklar. Es kann jedoch geschlossen werden, dass die Entzündung sowohl ein effektiver Trigger für eine Fibrosierung als auch ein lediglich assoziiertes Phänomen ist.

Nahezu alle kernhaltigen Zellen sezernieren Zytokine und Wachstumsfaktoren. Diese wiederum sind in der Lage, alle kernhaltigen Zellen zu beeinflussen. Zytokine steigern die Zytokinfreisetzung. Oxidativer Stress induziert die Expression von Wachstumsfaktoren und Zytokinen, während diese wiederum die oxidative Belastung steigern. In diesem für den Beobachter kaum zu überschauenden Netzwerk gelingt es zur Zeit nur schwerlich, Ursachen und Wirkungen zu trennen, da den meisten pathogenetischen Gliedern beiderlei Bedeutung zukommt.

\section{Schlussfolgerung}

Die pulmonale Toxizität stellt eine wichtige und dosislimitierende Komplikation lokaler und systemischer zytoreduktiver Therapien dar. Neben Erkenntnissen über die Mechanismen der therapie-assoziierten Lungenschädigungen ermöglichen sensitive und spezifische diagnostische Verfahren ein individuelles, dosisadaptiertes und damit dosisoptimiertes Vorge- hen. Hier kommt den Markern des pulmonalen oxidativen Stress eine vorrangige Rolle zu.

Die quantitative wie qualitative Einschätzung und gezielte Beeinflussung der oxidativen Belastung, z.B. durch systemische oder zukünftig möglicherweise auch topische Applikation von Anti-Oxidantien, könnte die Prognose der Patienten sowohl unter kurativen als auch unter palliativen multimodalen Therapieschemata verbessern.

\section{Literatur}

${ }^{1}$ Jeremic B, Shibamoto Y, Acimovic L, Milisavljevic S. Hyperfractionated radiation therapy with or without concurrent lowdose daily carboplatin etoposide for stage III non-small-cell lung cancer. A randomized study. J Clin Oncol 1996; 14: 1065 1070

${ }^{2}$ Komaki R, Scott CB, Sause WT. Induction cisplatin/vinblastine and irridation vs. irridation in unresectable squamous cell lung cancer: failure patterns by cell type in RTOG 88-08/EGOG 4588. Int J Radiat Oncol Biol Phys 1997; 39: 537 - 544

3 Segawa Y, Takigawa N, Kataoka M, Takata I, Fujimoto N, Ueoka $\mathrm{H}$. Risk factors for development of radiation pneumonitis following radiation therapy with or without chemotherapy for lung cancer. Int J Radiat Oncol Biol Phys 1997; 39: 91 - 98

${ }^{4}$ Svane G, Rotstein S, Lax I. Influence of radiation therapy on lung tissue in breast cancer patients-CT-assessed density changes 4 years after completion of radiotherapy. Acta Oncol 1995; 34: $845-849$

${ }^{5}$ Theuws JCM, Kwa SLS, Waagenar AC. Dose effect relations for early local pulmonary injury after irridation for malignant lymphoma and breast cancer. Radiother Oncol 1998; 48: 33 43

${ }^{6}$ Einhorn L, Krause M, Hornback N. Enhanced pulmonary toxicity with bleomycin and radiotherapy in oat cell lung cancer. Cancer 1976; 37: $2414-2416$

${ }^{7}$ Ma LD, Taylor GA, Wharam MD, Wiley JM. „Recall“ pneumonitis: adriamycin potentiation of radiation pneumonitis in two children. Radiology 1993; 187: 465 - 467

8 Trask C, Joannides T, Harper P. Radiation-induced lung fibrosis after treatment of small cell carcinoma of the lung with very high-dose cyclophosphamide. Cancer 1985; 55: 57 - 60

${ }^{9}$ Halliwell B. Reactive oxygen species in living systems: source, biochemistry, and role in human disease. Am J Med 1991; 91 (Suppl 3C): 14S - 22S

${ }^{10}$ Halliwell B, Gutteridge JMC, Cross CE. Free radicals, antioxidants, and human disease: where are we now. J Lab Clin Med 1992; 119: $598-620$

11 Janssen YMW, Van Houten B, Borm PJA, Mossman BT. Cell and tissue response to oxidative damage. Lab Invest 1993; 69: $261-274$

12 Poli G, Parola M. Oxidative damage and fibrogenesis. Free Radic Biol Med 1997; 22: 287 - 305

${ }^{13}$ Rochester CL, Elias JA. Cytokines and cytokine networking in the pathogenesis of interstitial and fibrotic lung disorders. Sem Resp Med 1993; 14: 389 - 416

${ }^{14}$ Gutteridge JMC, Mumby S, Quinlan GJ, Chung KF. Pro-oxidant iron is present in human pulmonary epithelial lining fluid: implications for oxidative stress in the lung. Biochem Biophys Res Commun 1996; 220: 1024 - 1027

15 Zweier JL, Duke SS, Kuppusamy P, Sylvester JT, Gabrielson EW. Electron paramagnetic resonance evidence that cellular oxyen toxicity is caused by the generation of superoxide and hydroxyl free radicals. FEBS-Lett 1989; 252: 12 - 16

${ }^{16}$ Gross NJ. Pulmonary effects of radiation therapy. Ann Int Med 1977; 86: 81 - 92 
17 Malik SW, Myers JL, DeRemee RA, Specks U. Lung toxicity associated with cyclophosphamide use - two distinct patterns. Am J Respir Crit Care Med 1996; 154: 1851 - 1856

18 Padley S, Adler B, Hansell D, Müller N. High-resolution computed tomography of drug-induced lung disease. Clin Radiol 1992; 46: $232-236$

${ }^{19}$ Abratt RP, Willcox PA. The effect of irradiation on lung function and perfusion in patients with lung cancer. Int J Radiat Oncol Biol Phys 1995; 31: 915 - 919

${ }^{20}$ Marks LB, Munley MT, Bentel GC. Physical and biological predictors of changes in whole-lung function following thoracic irradiation. Int J Radiat Oncol Biol Phys 1997; 39: 563 - 570

${ }^{21}$ Maasilta P, Hallman M, Taskinen E, Kivisaari L, Mattson K. Bronchoalveolar lavage fluid findings following radiotherapy for non-small cell lung cancer. Int J Radiat Oncol Biol Phys 1993; 26: $117-123$

22 White DA, Kris MG, Stover DE. Bronchoalveolar lavage cell population in bleomycin lung toxicity. Thorax 1987; 42: 551 552

${ }^{23}$ Cooper JAD, White DA, Matthay RA. Drug-induced pulmonary disease, part 1: cytotoxic drugs. Am Rev Respir Dis 1986; 133: $321-340$

${ }^{24}$ Koh DW, Castro M. Pulmonary Toxicity of Chemotherapeutic Drugs. In: Perry, MC. The Chemotherapy Sourcebook. Baltimore: Williams and Wilkins, 1996: 665 - 695

${ }^{25}$ Lind PARM, Gagliardi G, Wennberg B, Fornander T. A descriptive study of pulmonary complications after postoperative radiation therapy in node-positive stage II breast cancer. Acta Oncol 1997; 36: $509-515$

${ }^{26}$ Lingos TI, Recht A, Vicini F, Abner A, Silver B, Harris JR. Radiation pneumonitis in breast cancer patients treated with conservative surgery and radiation therapy. Int J Radiat Oncol Biol Phys 1991; 21: 355 - 360

${ }^{27}$ Monson JM, Stark P, Reilly JJ. Clinical radiation pneumonitis and radiographic changes after thoracic radiation therapy for lung carcinoma. Cancer 1998; 82: 842 - 850

${ }^{28}$ Castro M, Veeder MH, Mailliard JA, Tazelaar HD, Jett JR. A prospective study of pulmonary function in patients receiving mitomycin. Chest 1996; 109: 939 - 944

${ }^{29}$ Pavlakis N, Bell DR, Millward MJ, Levi JA. Fatal pulmonary toxicity resulting from treatment with gemcitabine. Cancer 1997; 80: $286-291$

30 Simpson AB, Paul J, Graham J, Kaye SB. Fatal bleomycin pulmonary toxicity in the west of Scotland 1991-95: a review of patients with germ cell tumours. Br J Cancer 1998; 78: $1061-1066$

${ }^{31}$ Morgan GW, Breit SN. Radiation and the lung: a reevaluation of the mechanisms mediating pulmonary injury. Int J Radiat Oncol Biol Phys 1995; 31: 361 - 369

32 Gibson PG, Bryant DH, Morgan GW. Radiation-induced lung injury: a hypersensitivity pneumonitis?. Ann Int Med 1988; 109: $288-291$

${ }^{33}$ Vujaskovic Z, Down JD, van t'Veld AA. Radiological and functional assessment of radiation-induced lung injury in the rat. Exp Lung Res 1998; 24: 137 - 148

${ }^{34}$ Schnabel A, Richter C, Bauerfeind S, Gross WL. Bronchoalveolar lavage cell profile in methotrexate induced pneumonitis. Thorax 1997; 52: 377 - 379

${ }^{35}$ Mark GJ, Lehimgar-Zadeh A, Ragsdale BD. Cyclophosphamide pneumonitis. Thorax 1978; 33: 89 - 94

${ }^{36}$ Tucker AS, Newman AJ, Alvorado C. Pulmonary pleural and thoracic changes complicating chemotherapy. Radiology 1977; 125: 805

${ }^{37}$ Crouch E. Pathobiology of pulmonary fibrosis. Am J Physiol Lung Cell Mol Physiol 1990; 259: L159 - L184
38 Reed CR, Glauser FL. Drug-induced noncardiogenic pulmonary edema. Chest 1991; 100: 1120 - 1124

${ }^{39}$ Beinert T, Binder D, Oehm C. Increased levels of vascular endothelial growth factor in bronchoalveolar lavage of patients with bronchial carcinoma-effect of tumour activity and oxidative stress due to radio-chemotherapy? Eur J Med Res 1999; 4: $328-334$

${ }^{40}$ Rubin P, Johnston CJ, Williams JP, McDonald S, Finkelstein JN. A perpetual cascade of cytokines postirradiation leads to pulmonary fibrosis. Int J Radiat Oncol Biol Phys 1995; 33: 99 - 109

${ }^{41}$ Sage H, Farin FM, Striker GE, Fisher AB. Granular pneumocytes in primary culture secrete several major components of the extracellular matrix. Biochemistry 1983; 22: $2148-2155$

42 Vergara JA, Raymond U, Thet LA. Changes in lung morphology and cell number in radiation pneumonitis and fibrosis: a quantitative ultrastructural study. Int J Radiat Oncol Biol Phys 1987; $13: 723-732$

${ }^{43}$ Hunninghake GW, Gadek JE, Kawanami O, Ferrans VJ, Crystal RG. Inflammatory and immune processes in the human lung in health and disease: Evaluation by bronchoalveolar lavage. Am J Pathol 1979; 97: 149 - 206

${ }^{44}$ Geara FB, Komaki R, Tucker SL, Travis EL, Cox JD. Factors influencing the development of lung fibrosis after chemoradiation for small cell carcinoma of the lung: Evidence for inherent interindividual variation. Int J Radiat Oncol Biol Phys 1998; 41: $279-286$

45 Johnston CJ, Stripp BR, Piedbeouf B. Inflammatory and epithelial responses in mouse strains that differ in sensitivity to hyperoxic injury. Exp Lung Res 1998; 24: 189 - 202

46 Barquinero JF, Barrois L, Caballin MR. Occupational exposure to radiation induces an adaptive response in human lymphocytes. Int J Radiat Biol 1995; 67: 187 - 191

47 Youngblom JH, Wiencke JK, Wolff S. Inhibition of the adaptive response of human lymphocytes to very low doses of ionizing radiation by the protein synthesis inhibitor cycloheximide. Mutat Res 1989; 227: 257 - 261

${ }^{48}$ Cohen DS, Palmer E, Welch WJ, Sheppard D. The response of guinea pig airway epithelial cells and alveolar macrophages to environmental stress. Am J Respir Cell Mol Biol 1991; 5: 133 143

49 Deitch EA, Beck SC, Cruz NC, De Maio A. Induction of heat shock gene expression in colonic epithelial cells after incubation with Escherichia coli or endotoxin. Crit Care Med 1995; 23: 1371 1376

${ }^{50}$ Javadpour M, Kelly CJ, Chen G, Stokes K, Leahy A, BouchierHayes DJ. Thermotolerance induces heat shock protein 72 expression and protects against ischaemia-reperfusion-induced lung injury. Br J Surg 1998; 85: 943 - 946

51 Jornot L, Mirault ME, Junod AF. Differential expression of hsp70 stress points in human endothelial cells exposed to heat shock and hydrogen peroxide. Am J Respir Cell Mol Biol 1991; 5: $265-275$

52 Polla BS, Kantengwa S, Francois D. Mitochondria are selective targets for the protective effects of heat shock against oxidative injury. Proc Natl Acad Sci USA 1996; 93: 6458 - 6463

${ }^{53}$ Ikushima T, Aritomi H, Morisita J. Radioadaptive response: efficient repair or radiation-induced DNA damage in adapted cells. Mutat Res Fundam Mol Mech Mutagen 1996; 358: 193 198

${ }^{54}$ Ho YS, Dey MS, Crapo JD. Antioxidant enzyme expression in rat lungs during hyperoxia. Am J Physiol 1996; 270: L810 - L818

${ }^{55}$ Preville X, Salvemini F, Giraud S. Mammalian small stress proteins protect against oxidative stress through their ability to increase glucose-6-phosphate dehydrogenase activity and by maintaining optimal cellular detoxifying machinery. Exp Cell Res 1999; 247: 61 - 78 
56 Gorman AM, Heavey B, Creagh E, Cotter TG, Samali A. Antioxidant-mediated inhibition of the heat shock response leads to apoptosis. FEBS-Lett 1999; 445: 98 - 102

57 Park YM, Han MY, Blackburn RV, Lee YL. Overexpression of HSP25 reduces the level of TNFalpha-induced oxidative damage biomarker, 8-hydroxy-2'deoxyguanosine, in L929 cells. J Cell Physiol 1998; 174: 27 - 34

58 Wong HR, Menendez IY, Ryan MA, Denenberg AG, Wispe JR. Increased expression of heat shock protein-70 protects A549 cells against hyperoxia. Am J Physiol Lung Cell Mol Physiol 1998; 275: L836 - L841

59 Satoh M, Hirayoshi K, Yokota SI, Hosokawa N, Nagata K. Intracellular interaction of collagen-specific stress protein HSP47 with newly synthesized procollagen. J Cell Biol 1996; 133: $469-483$

${ }^{60}$ Nagata K, Saga S, Yamada KM. A major collagen-binding protein of chick embryo fibroblasts is a novel heat shock protein. J Cell Biol 1986; 103: 223 - 229

${ }^{61}$ Razzaque MS, Hossain MA, Kohno S, Taguchi T. Bleomycininduced pulmonary fibrosis in rat is associated with increased expression of collagen-binding heat shock protein (HSP) 47. Virchows Arch 1998; 432: 455 - 460

62 Sunamoto M, Kuze K, Tsuji $H$. Antisense oligonucleotides against collagen-binding stress protein HSP47 suppress collagen accumulation in experimental glomerulonephritis. Lab Invest 1998; 78: 967 - 972

63 Bonay M, Soler P, Riquet M, Battesti JP, Hance AJ, Tazi A. Expression of heat shock proteins in human lung and lung cancer. Am J Respir Cell Mol Biol 1994; 10: 453 - 461

64 Spitz DR, Dewey WC, Li GC. Hydrogen peroxide or heat shock induces resistance to hydrogen peroxide in chinese hamster fibroblasts. J Cell Physiol 1987; 131: 364 - 373

${ }^{65}$ Wong HR, Mannix RJ, Rusnak JM. The heat shock response attenuates lipopolysaccaride-mediated apoptosis in cultured sheep pulmonary artery endothelial cells. Am J Respir Cell Mol Biol 1996; 15: 745 - 751

${ }^{66}$ Hamilton RFJ, Hazbun ME, Jumper CA, Eschenbacher WL, Holian A. 4-hydroxynonenal mimics ozone-induced modulation of macrophage function ex vivo. Am J Respir Cell Mol Biol 1996; 15: $275-282$

${ }^{67}$ Kindas-Mugge I, Pohl WR, Zavadova E. Alveolar macrophages of patients with adult respiratory distress syndrome express high levels of heat shock protein 72 mRNA. Shock 1996; 5: 184 - 189

68 Vignola AM, Chanez P, Polla BS, Vic P, Godard P, Bousquet J. Increased expression of heat shock protein 70 on airway cells in asthma and chronic bronchitis. Am J Respir Cell Mol Biol 1995; 13: $683-691$

${ }^{69}$ Thrall RS, Barton RW, D'Amato DA, Sulavik SB. Differential cellular analysis of bronchoalveolar lavage fluid obtained at various stages during the development of bleomycin-induced pulmonary fibrosis in the rat. Am Rev Respir Dis 1982; 126: $488-492$

70 Travis EL, Harley RA, Fenn JO, Klobukowski CJ, Hargrove HB. Pathologic changes in the lung following single and multifraction irradiation. Int J Radiat Oncol Biol Phys 1977; 2: 475 490

71 Ward HE, Kemsley L, Davies L, Holecek M, Berend N. The pulmonary response to sublethal thoracic irradiation in the rat. Radiat Res 1993; 136: 15 - 21

72 Aso Y, Yoneda K, Kikkawa Y. Morphological and biochemical study of pulmonary changes induced by bleomycin in mice. Lab Invest 1976; 35: $558-568$

73 Jones AW, Reeve NL. Ultrastructural study of bleomycininduced pulmonary changes in mice. J Pathol 1978; 124: 227 233
74 Guerry-Force ML, Perkett EA, Brigham KL, Meyrick B. Early structural changes in sheep lung following thoracic irradiation. Radiat Res 1988; 114: 138 - 153

75 Barnett D. Preclinical toxicology of ifosfamide. Semin Oncol 1982; 9 (Suppl 1): $8-13$

${ }^{76}$ Fahey PJ, Utell MJ, Mayewski RJ, Wandtke JD, Hyde RW. Early diagnosis of bleomycin pulmonary toxicity using bronchoalveolar lavage in dogs. Am Rev Respir Dis 1982; 126: 126 - 130

77 Hay J, Shahzeide S, Laurent G. Mechanisms of bleomycininduced lung damage. Arch Toxicol 1991; 65: 81 - 94

${ }^{78}$ Kanofsky JR. Singlet oxygen production by bleomycin. J Biol Chem 1986; 261: $13546-13550$

${ }^{79}$ Slosman DO, Costabella PM, Roth M, Werlen G, Polla BS. Bleomycin primes monocytes-macrophages for superoxide production. Eur Respir J 1990; 3: 772 - 778

${ }^{80}$ Scheule RK, Perkins RC, Hamilton R, Holian A. Bleomycin stimulation of cytokine secretion by the human alveolar macrophage. Am J Physiol Lung Cell Mol Physiol 1992; 262: L386 - L391

${ }^{81}$ Colvin M. The comparative pharmacology of cyclophosphamide and ifosfamide. Semin Oncol 1982; 9 (Suppl. 1): 2 - 7

82 Gurtoo HL, Hipkens JH, Sharma SD. Role of glutathione in the metabolism-dependent toxicity and chemotherapy of cyclophosphamide. Cancer Res 1981; 41: 3584 - 3591

83 Patel JM, Block ER. Cyclophosphamide-induced depression of the antioxidant defense machanisms of the lung. Exp Lung Res 1985; 8: 153 - 165

${ }^{84}$ Issels RD, Meier TH, Müller E, Multhoff G, Wilmanns W. Ifosfamide induced stress response in human lymphocytes. Molec Aspects Med 1993; 14: 281 - 286

${ }^{85}$ Sinha BK, Politi PM. Anthracyclines. Cancer Chemoth Biol Modif 1990; $11: 45-57$

${ }^{86}$ Gianni L, Vigano Lanzi L, Niggellar M, Malatesta V. Role of daunosamine and hydroxyacetyl side chain in reaction with iron and lipid peroxidation by anthracyclines. J Natl Cancer Inst 1988; 80: $1104-1111$

${ }^{87}$ Gille L, Nohl H. Analyses of the molecular mechanism of adriamycin-induced cardiotoxicity. Free Radic Biol Med 1997; 23: $775-782$

${ }^{88}$ Krishna MC, DeGraff W, Tamura S. Mechanisms of hypoxic and aerobic cytotoxicity of mitomycin $C$ in chinese hamster V79 cells. Cancer Res 1991; 51: $6622-6628$

${ }^{89}$ Murrell GAC, Francis MJO, Bromley L. Modulation of fibroblast proliferation by oxygen free radicals. Biochem J 1990; 265: $659-665$

${ }^{90}$ Fuks Z, Persaud RS, Alfieri A. Basic fibroblast growth factor protects endothelial cells against radiation-induced programmed cell death in vitro and in vivo. Cancer Res 1994; 54: 2582 2590

${ }^{91}$ Cochrane CG. Mechanisms of oxidant injury of cells. Molec Aspects Med 1991; 12: 137 - 147

${ }^{92}$ Lelli JL, Becks LL, Dabrowska MI, Hinshaw DB. ATP converts necrosis to apoptosis in oxidant-injured endothelial cells. Free Radic Biol Med 1998; 25: $694-702$

93 Roitt IM, Brostoff J, Male DK. Kurzes Lehrbuch der Immunologie. Stuttgart, New York: Georg Thieme Verlag, 1991: 79 - 114

${ }_{94}$ Elias JA, Schreiber AD, Gustilo K. Differential interleukin-1 elaboration by unfractionated and density fractionated human alveolar macrophages and blood monocytes: relationship to cell maturity. J Immunol 1985; 135: 2198 - 2204

${ }^{95}$ Weswers MD, Herzyk DJ. Alveolar macrophages differ from blood monocytes in human IL-1 beta release. Quantitation by enzyme-linked immunoassay. J Immunol 1989; 143: 1635 1641 
96 O’Brien-Ladner A, Nelson ME, Kimler BF, Wesselius LJ. Release of interleukin-1 by human alveolar macrophages after in vitro irradiation. Radiat Res 1993; 136: 37 - 41

97 Parola M, Pinzani M, Casini A. Stimulation of lipid peroxidation or 4-hydroxynonenal treatment increases procollagen alpha (I) gene expression and synthesis in human liver fat storing cells. Biochem Biophys Res Commun 1993; 194: 1044 - 1050

98 Curzio M. Interaction between neutrophils and 4-hydroxyalkenals and consequences on neutrophil motility. Free Radic Res Commun 1988; 5: 55 - 66

${ }^{99}$ Curzio M, Esterbauer H, Dianzani MU. Chemotactic acitivty of hydroxyalkenals on rat neutrophils. Int J Tissue React 1985; 7: $137-142$

100 Schreck R, Rieber P, Baeuerle PA. Reactive oxygen intermediates as apparently widely used messengers in the acitvation of NFkappa B transcription factor and HIV-1. EMBO Journal 1991; 10: $2247-2258$

101 Datta R, Hallahan DE, Kharbanda SM. Involvement of reactive oxygen intermediates in the induction of c-jun gene transcription by ionising radiation. Biochemistry 1992; 31: 8300 - 8306

102 Tischer E, Mitchell R, Hartman T. The human gene for vascular endothelial growth factor. Multiple protein forms are encoded through alternative exon splicing. J Biol Chem 1991; 266: 11947 - 11954

103 Messer G, Weiss EH, Baeuerle PA. Tumor necrosis factor beta (TNF-beta) induces binding to the NF-kappa B transcription factor to a high-affinity kappa B element in the TNF-beta promoter. Cytokine 1990; 2: 1 - 9

104 Libermann TA, Baltimore D. Acitvation of the interleukin- 6 gene expression through the NF-kappa B transcription factor. Mol Cell Biol 1990; 10: 2327 - 2334

${ }^{105}$ Kim SJ, Dehnez F, Kim KY, Holt JT, Sporn MB, Roberts AB. Acitvation of the second promoter of the transforming growth factor-beta1 gene by transforming growth factor-beta1 and phorbol ester occurs through the same target sequences. J Biol Chem 1989; 264: 19373 - 19378

106 Lin X, Wang Z, Gu L, Deuel TF. Functional analysis of the human platelet-derived growth factor A-chain promoter region. J Biol Chem 1992; 267: 25614 - 25619

107 Bonizzi G, Dejardin E, Piret B, Piette J, Merville MP, Bours V. Interleukin-1 induces nuclear factor kappaB in epithelial cells independently of the production of reactive oxygen intermediates. Eur J Biochem 1996; 242: 544 - 549

108 Duckett CS, Perkins ND, Leung K, Agranoff AB, Nabel GJ. Cytokine induction of nuclear factor kappaB in cycling and growth-arrested cells. Evidence for cell cycle-independent activation. J Biol Chem 1995; 270: 18836 - 18840

109 Staal FJJ, Roederer M, Herzenberg LA. Intracellular thiols regulate the activation of nuclear factor Kappa B and transcription of human immunodeficiency virus. Proc Natl Acad Sci USA 1990; 87: 9943 - 9949

110 Burdon RH. Superoxide and hydrogen peroxide in relation to mammalian cell proliferation. Free Radic Biol Med 1995; 18: 775 - 794

111 Babior BM. Oxygen-dependent microbial killing by phagocytes. N Engl J Med 1978; 298: 659 - 668

112 Weiss SS. Tissue destruction by neutrophils. N Engl J Med 1989; 320: 365 - 376

113 Behr J. Interstitielle Lungenerkrankungen und Oxidanzienbelastung. Pathogenetisches Bindeglied zwischen Alveolitis und Fibroblastenstimulation. Fortschr Med 1998; 116: 41 - 42

114 Fox RB, Hoidal JR, Brown DM, Repine JE. Pulmonary inflammation due to oxygen toxicity: involvement of chemotactic factors and polymorphonuclear leukocytes. Am Rev Respir Dis 1981; 123: $521-523$
115 Biemond P, Van Eijk HG, Swaak AJG, Koster JF. Iron mobilization from ferritin by superoxide derived from stimulated polymorphonuclear leukocytes: Possible mechanisms in inflammation disease. J Clin Invest 1984; 73: 1576 - 1579

116 Gutteridge JMC. Iron promoters of the Fenton reaction and lipid peroxidation can be released from haemoglobin by peroxides. FEBS-Lett 1986; 201: 291 - 295

117 Gorbunov NV, Elsayed NM, Kisin ER, Kozlov AV, Kagan VE. Air blast-induced pulmonary oxidativ stress: Interplay among hemoglobin, antioxidants, and lipid peroxidation. Am J Physiol Lung Cell Mol Physiol 1997; 272: L320 - L334

118 Prober JS, Bevilacqua MP, Mendrick DC, Lapierre LA, Fiers W, Gimbrone J. Two distinct monokines, interleukin 1 and tumour necrosis factor, each independently induce biosynthesis and transient expression of the same antigen on the surface of cultured human vascular endothelial cells. J Immunol 1986; 136: 1680 - 1687

119 Meier B, Radeke HH, Selle S. Human fibroblasts release active oxygen species in response to interleukin-1 and tumour necrosis factor. Biochem J 1989; 263: 539 - 545

${ }^{120}$ Friedl HP, Till GO, Ryan US, Ward PA. Mediator-induced activation of xanthine oxidase in endothelial cells. FASEB J 1989; 3 : $2512-2518$

121 Phan SH, Gannon DE, Varani J, Ryan US, Ward PA. Xanthine oxidase acticity in rat pulmonary artery endothelial cells and its alterations by activated neutrophils. Am J Pathol 1989; 134 $1201-1211$

122 Halliwell B. Antioxidants and human disease: a general introduction. Nutr Rev 1997; 55: 44 - 49

123 Unemori EN, Bouhana KS, Werb Z. Vectorial secretion of extracellular matrix proteins, matrix-degrading proteinases, and tissue inhibitor of metalloproteinase by endothelial cells. J Biol Chem 1990; 265: 445 - 451

${ }^{124}$ Elias JA, Zitnik R, Ray P. Fibroblast immune-effector function. In: Phipps, R. Pulmonary fibroblast heterogeneity. Boca Raton: CRC Press, 1992. 295 - 322

125 Burdon RH, Rice-Evans C. Free radicals and the regulation of mammalian cell proliferation. Free Radic Res Commun 1989; 6: $345-358$

126 Travis EL, Down JD. Repair in mouse lung after split doses of X rays. Radiat Res 1981; 87: 166 - 174

127 Franko AJ, Sharplin J. Development of fibrosis after lung irridation in relation to inflammation and lung function in a mouse strain prone to fibrosis. Radiat Res 1994; 140: 347 - 355

128 Rubin P, Finkelstein J, Shapiro D. Molecular biology mechanisms in the radiation induction of pulmonary injury syndromes: interrelationship between the alveolar macrophage and the septal fibroblast. Int J Radiat Oncol Biol Phys 1992; 24: 93 101

129 Piguet PF, Kaufman S, Barazzone C, Muller M, Ryffel B, Eugster HP. Resistance of TNF/LT alpha double deficient mice to bleomycin-induced fibrosis. Int J Exp Pathol 1997; 78: 43 - 48

130 Thrall RS, Vogel SN, Evans R, Shultz LD. Role of tumor necrosis factor- $\alpha$ in the spontenaeous development of pulmonary fibrosis in viable motheaten mutant mice. Am J Pathol 1997; 151: $1303-1310$

\section{T. Beinert}

Medizinische Klinik und Poliklinik

m.S. Hämatologie und Onkologie

Charitè, Campus Mitte

10115 Berlin 